\title{
Changes in behaviour following a 'rank changeover by challenge' in the Nicobar long-tailed macaque (Macaca fascicularis umbrosus)
}

\author{
Arijit Pal $^{1,2}$, Honnavalli N. Kumara ${ }^{1, *}$, Avadhoot D. Velankar ${ }^{1,2}$, \\ Partha Sarathi Mishra ${ }^{1,3,4}$ and Mewa Singh ${ }^{4,5}$ \\ ${ }^{1}$ Sálim Ali Centre for Ornithology and Natural History, Coimbatore 641 108, India \\ ${ }^{2}$ Manipal Academy of Higher Education, Manipal 576 104, India \\ ${ }^{3}$ Bharathiar University, Coimbatore 641 046, India \\ ${ }^{4}$ Biopsychology Laboratory and Institution of Excellence, University of Mysore, Mysuru 570006 , India \\ ${ }^{5}$ Organismal Biology Unit, Jawaharlal Nehru Centre for Advance Scientific Research, Bengaluru 560 064, India
}

A rank changeover is a sexual strategy by primate males to gain access to reproductive females. We observed one such event in the Nicobar long-tailed macaque (Macaca fascicularis umbrosus) at the Great Nicobar Island, India. In the three and half months of the post-rank changeover period, the home range reduced significantly while there was no change in the intensity of range use and day range length. The sleeping sites in the post-rank changeover period were confined to the centre of the home range. The overall mating rate and aggressive mating approach by males increased significantly during the post-rank changeover period. The females developed sexual swelling and started soliciting the immigrated males within two weeks after the rank changeover event. During this period no female conceived, which suggests that they used situation-dependent receptivity with deceptive swelling as a counter strategy to avoid male aggression for copulation.

Keywords: Between-group encounters, grid use, Nicobar long-tailed macaque, rank changeover, reproductive behaviour.

IN many group-living species, dominance rank or status is a good predictor of mating success in both males and females ${ }^{1}$. This relation is strong among males in the species that mate polygynously ${ }^{2}$. Although the influence of social rank on mating success varies, a top rank can help a male to monopolize mating resources ${ }^{3}$. A male can acquire the top dominance rank in three different ways: (1) a rank changeover by challenging and defeating the present dominant male by a resident or an out-group male, (2) by forming a new group by ousting the resident males, or (3) through succession, after the death or emi-

*For correspondence. (e-mail: honnavallik@gmail.com) gration of the previous dominant male ${ }^{4}$. In large groups of the Japanese macaque (Macaca fuscata), when the prime male (alpha) dies or becomes inactive, hierarchy shifts to the next dominant male without much aggression, whereas in smaller groups, it happens through an aggressive challenge by the outer males ${ }^{5,6}$. van Noordwijk and van Schaik $^{7}$ reported from a long-term study on the long-tailed macaque (Macaca fascicularis) that resident males generally succeeded in reaching the top rank (100\% of replacements), while outer group males were less often successful (29\% of replacements). Moreover, in crested macaque (Macaca nigra) of South Sulawesi, 56\% of the rank changeover events happen through severe aggressive fight between a top rank male and outer group male, where $44 \%$ rank changeover occur events after opportunistic invade of outer group male when the resident male left the group or was injured ${ }^{8}$.

A sudden change in the social organization of a group has immense impact on its members ${ }^{9,10}$. In the case of a rank changeover with an aggressive approach by a challenger male towards the dominant male of the group, the duration and intensity of the agonistic interactions vary with the response of the prime male $\mathrm{e}^{9,10}$. After being defeated, the former dominant male may leave the group immediately ${ }^{8,10}$, or stay with the group as a subordinate individual ${ }^{5,11,12}$. The new alpha male may be involved in agonistic interactions to establish dominance over the other group members ${ }^{13,14}$. The new dominant male tries to increase reproductive access by initiating mating with adult females of the group ${ }^{12}$. If most females in the group are lactating or are in the non-cycling phase, they may not positively respond to the mating-initiation approaches by the male. In such a situation, the male may adopt strategies like forced mating with a female ${ }^{15}$ and probable infanticide $^{16-18}$ to attain reproductive success. In response, the females may also adopt various counter-strategies such as group defence to protect themselves from sexual 


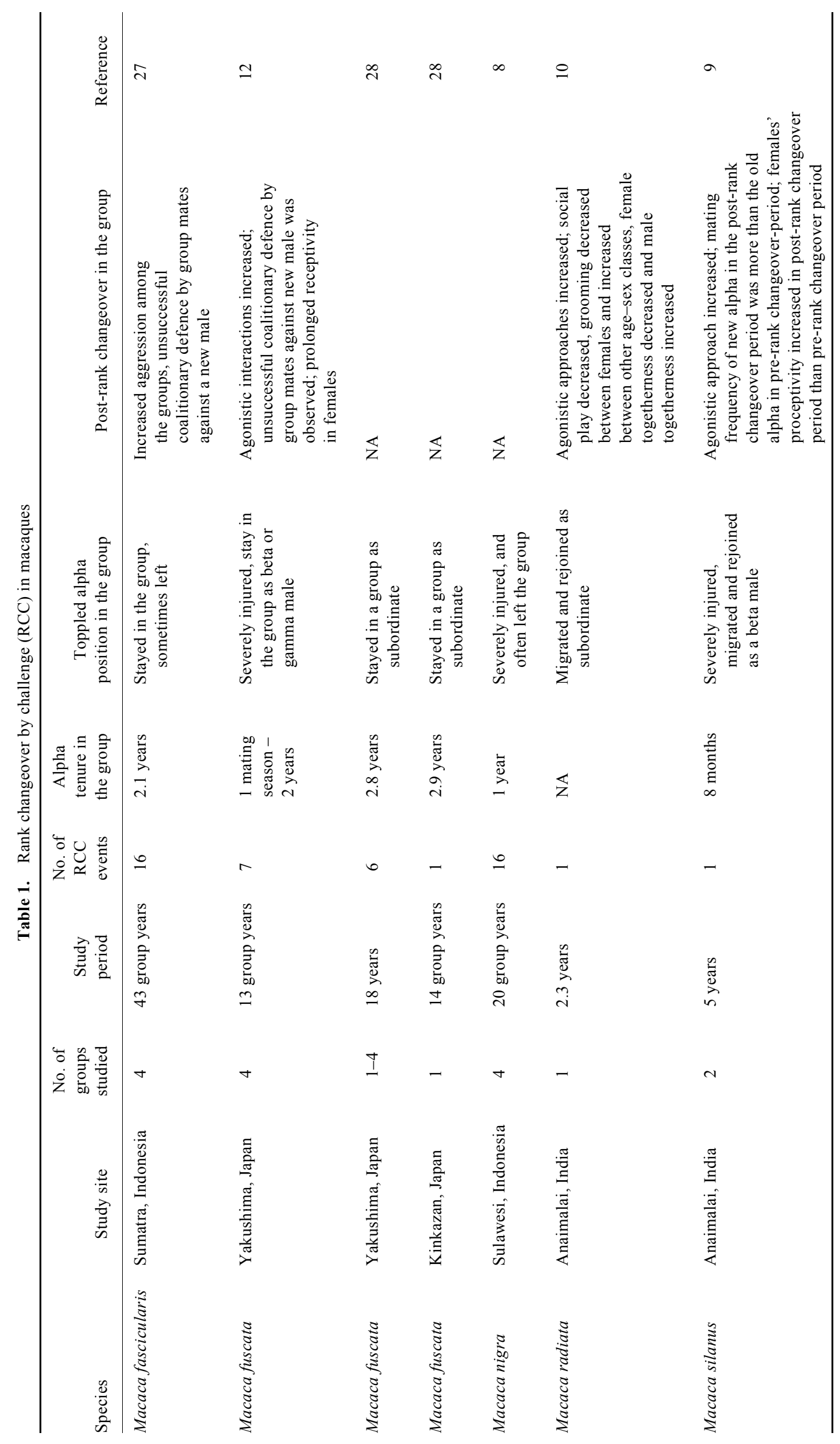




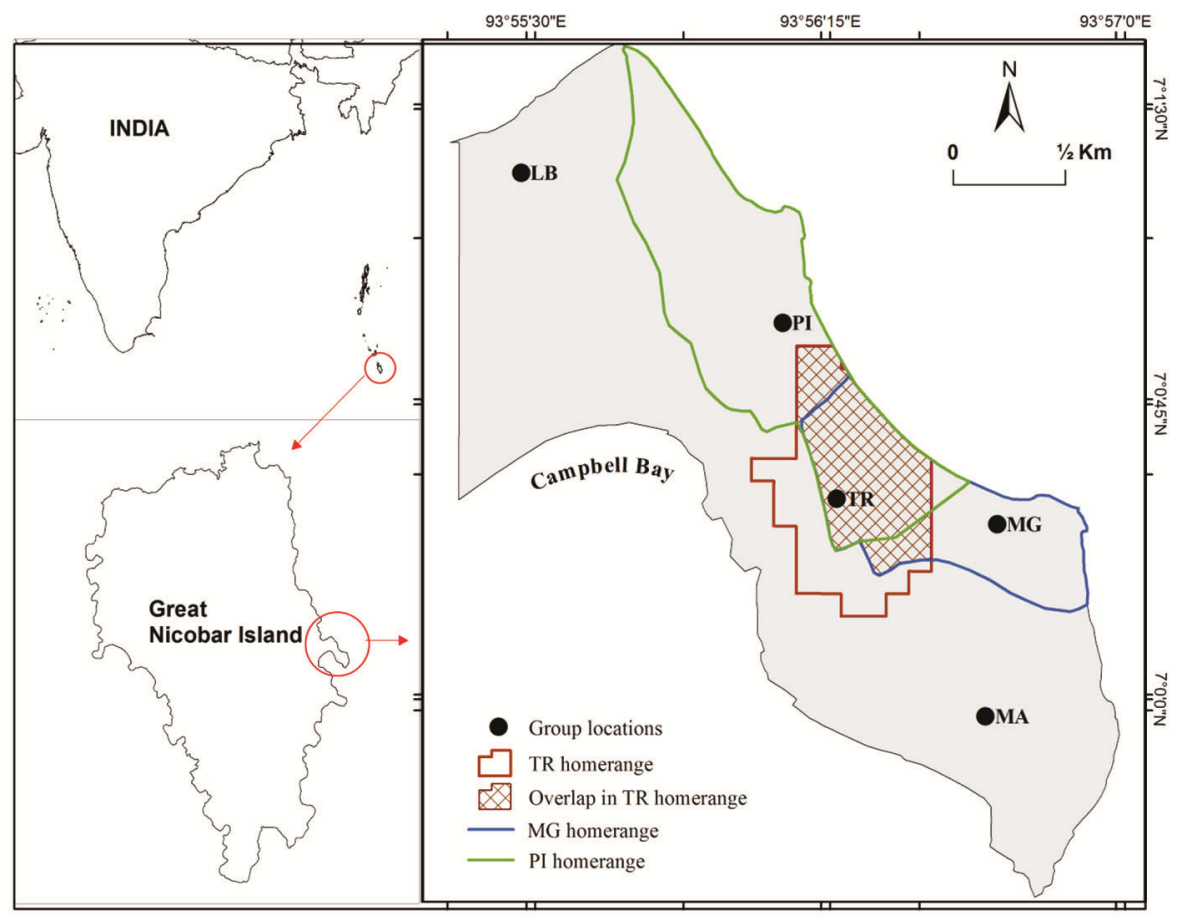

Figure 1. An overview of the study area showing locations of the macaque groups with their respective home ranges in the Great Nicobar Island, India (the overlapping regions are crosshatched).

coercion $^{19}$, situation-dependent receptivity ${ }^{5}$, deceptive swelling ${ }^{19-23}$, abrupt infant weaning ${ }^{24,25}$ and emigration from the group ${ }^{26}$ to secure the survival of their infants.

A rank changeover resulting from a challenge by an outsider male is infrequent but observed across macaques; yet only in a few species (M. fascicularis $^{27} ;$ M. fuscata $^{12,28} ;$ M. nigra $^{8} ;$ M. radiata $^{10} ;$ M. silenus $\left.^{9}\right)$. Most of the events are seen from the point of male migration and factors that determined successful migration in acquiring top rank in the group ${ }^{8,27,28}$. However, the immediate effect of rank changeover on the behavioural ecology of the group is highly limited (Table 1).

We conducted a long-term study on the ecology and social behaviour of the Nicobar long-tailed macaque (M. fascicularis umbrosus) in the Nicobar Islands, India. In these Islands, long-tailed macaques have a mean group size of 41.3 with about $13 \%$ of adult males and $30 \%$ of adult females ${ }^{29}$. The long-tailed macaque is a year-round breeder showing a birth peak between July and November ${ }^{30}$, and has an inter-birth interval of about 390 days $^{20}$. It has a despotic social structure ${ }^{31}$, where paternity concentration of the top dominant male is high ${ }^{27}$. Therefore, in long-tailed macaques the social rank of a male has an impact on the mating success, which makes rank changeover a successful reproductive strategy for the males. The long-tailed macaques fall under the high contest range ${ }^{31}$, thus we expected a rank changeover by challenge to result in male initiated copulations, some of them with aggressive approaches ${ }^{15}$, and its associated consequences such as possible infanticide ${ }^{6}$, and a variety of counter-strategies by the females such as group defence or pseudo sexual swelling ${ }^{32,33}$. It has been observed in Nilgiri langurs (Semnopithecus johnii) that after a rank changeover by an outsider male challenge, the group reduced and shifted its home range even to a resource-poor area, but resulting in less frequent intergroup encounters than before the shift ${ }^{34}$. Maybe following the rank changeover, the home range of the group might shift or reduce in size to avoid intergroup encounters during the period of social instability.

As the rank changeover by challenge has been reported in the other subspecies of long-tailed macaques (M. fascicularis fascicularis $)^{11,27}$, we anticipated the same event in our study population. We did indeed observe such rank changeover for the sub-species. Here we report the consequences of this rank changeover by challenge on the behaviour of the Nicobar long-tailed macaques, which will provide additional information to fill the lacuna in understanding the effect of rank changeover events in group-living macaques.

\section{Materials and methods}

\section{Study site and subjects}

The study was conducted in and around Campbell Bay, a village of $4.54 \mathrm{sq}$. $\mathrm{km}$ area in the Great Nicobar island lying between $93^{\circ} 55^{\prime} 8.417^{\prime \prime}-93^{\circ} 56^{\prime} 51.95^{\prime \prime} \mathrm{E}$ and $7^{\circ} 1^{\prime} 39.34^{\prime \prime}-$ $6^{\circ} 59^{\prime} 31.47^{\prime \prime} \mathrm{N}$. The major forest and habitat types in the study site include littoral forest dominated by Pandanus 
odoratistimus, evergreen hill forest, and small homeorchards and coconut plantations ${ }^{35}$. The study site was inhabited by five groups (LB, PI, TR, MG, MA) of Nicobar long-tailed macaques, with an average group size of 35.60 animals/group, and density of 1.10 groups/ sq. km, or 39.16 macaques/sq. km (Figure 1). Whereas all groups were monitored for demography and population dynamics, for convenient logistic reasons, TR was our focal group for a long-term behavioural study. Just before the rank changeover by challenge by an outgroup male, the study group comprised of 18 individuals, including two adult males (HK, RY), eight adult females (AU, BY, LA, NI, PM, RE, ST, TE), one subadult male (MF), four juveniles (BA, KU, OE, UK) and three infants (AI, BN, PT). RY was the alpha male.

\section{Ethical note}

We adhered to all guidelines and regulations of India and of the study area while conducting this research. The study was approved by the ethical committee of Sálim Ali Centre for Ornithology and Natural History (SACON), Coimbatore, before its commencement. All necessary permits to enter protected areas and tribal areas were acquired from the Chief Wildlife Warden of the Andaman and Nicobar Forest Department and the Assistant Commissioner of Andaman and Nicobar Administration (Permit No. CWLW/WL/134/566). Further, the authors have no conflict with any party regarding this article.

\section{Data collection}

We spent the first three months, viz. May-July 2013, to habituate the monkeys to the presence of observers. Following this, we carried out a $2781 \mathrm{~h}$ study between August 2013 and December 2015. During this period, we identified all individuals using their facial markings and features and wound marks on the body. Based on the physical appearance of the monkeys, the age classes that we have considered are: adult: $\geq 4$ years, sub-adult: $2.5-4$ years, juvenile: 6 months-2.5 years, and infant: $\leq 6$ months (ref. 29). We collected the group count and demography data when all individuals were crossing a road or moving for roosting in a single line.

Three observers independently collected data on ecology and ranging, between-group encounters and reproductive behaviour using different methodologies and thus the effort for studying these behaviours varied. Observers followed the group for an entire day from 0600 to $1830 \mathrm{~h}$. The group mostly ranged in a high visibility area and only occasionally moved into dense undergrowth or a restricted region like the premises of the Defence and Coast Guard, and the time spent there was not included in the total duration of observation during that day. The geo-coordinate of the visually calculated centre of the group were recorded using handheld geographic positioning system (Garmin GPSmap 76CSx) every 30 min while following the group ${ }^{36}$. The geo-coordinates of the sleeping site after termination and before initiation of daily movement of the group were recorded ${ }^{37}$. The presence/ absence of individuals in the group and their identity was also recorded every day.

Data on the between-group encounters were collected as event sampling ${ }^{38}$. We considered between-group encounters as those occasions when two groups came close to each other in the visible range or in auditory contact that is about $50 \mathrm{~m}$ of proximity ${ }^{39}$. A between-group encounter was classified as 'non-aggressive' if interactions were limited only to visual and vocal exchanges, and 'aggressive' when the groups were involved in aggressive vocal and physical interactions that included chasing and fighting ${ }^{40}$. We calculated the frequency of overall encounter as well as for each class of encounter by dividing the number of encounters by the number of observation hours per day.

We used the all occurrences sampling method to collect data on copulations ${ }^{38}$. We recorded the identity and activity of each individual involved in pre-copulatory, copulatory and post-copulatory activity along with mating approaches ${ }^{41}$. We considered mating to have occurred when there was a mounting with intromission and sequence of pelvic thrusts ${ }^{42}$. Ano-genital presentation and reaching back to a female, and genital inspection and aggressive approach for mating by a male were considered as mating initiation approaches ${ }^{43}$. Data on presents, mounts and copulations were collected through all occurrence sampling. The records on rank changeover and migration events were obtained through ad libitum sampling $^{38}$.

\section{Analysis}

The rank changeover event took place on 14 October 2013, and the analysis was performed on data collected between July 2013 and January 2014. We considered the period from July 2013 to 14 October 2013 as the pre-rank changeover period, and that from 14 October 2013 to January 2014 as the post-rank changeover period. All data were accordingly segregated and compared.

Between-group encounters: The between-group encounter data were collected for $864.75 \mathrm{~h}$ (111 days) with $388.75 \mathrm{~h}$ (60 days) and $476 \mathrm{~h}$ (51 days) in the pre- and the post-rank changeover periods respectively. Each observation day was considered as one sample. The betweengroup encounter rates of each day were calculated using the number of interactions (overall, non-aggressive and aggressive) recorded against observation hours of that day, and presented as interactions per hour. 
(a)

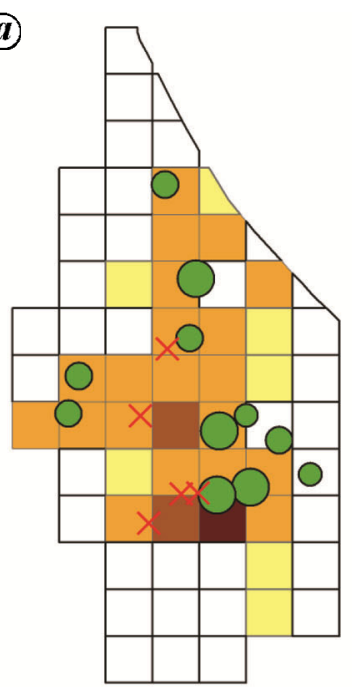

Sleeping site use
Grid use (b)

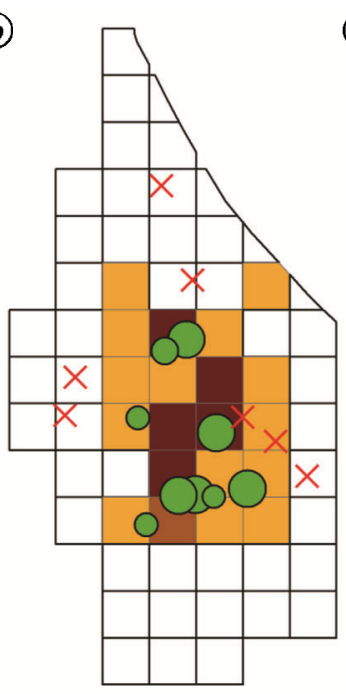

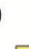
0 (c)

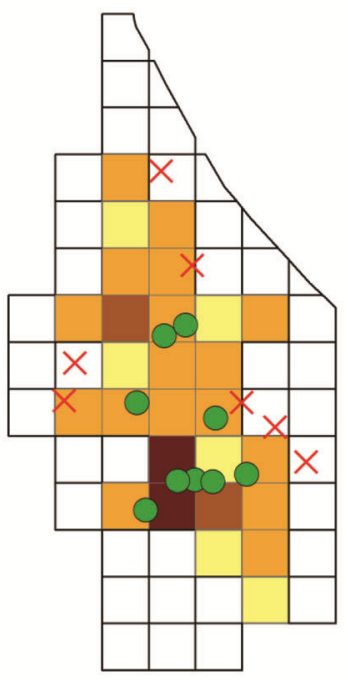

$5.1-10 \% \bigcirc>10 \%$

$6.7-10 \%$
$>10 \%$

Figure 2. Intensity of use of grid cells and sleeping sites by study group TR: (a) pre-rank changeover pattern; (b) post-rank changeover pattern and (c) control.

Ranging pattern: The shape file of the study area was overlaid with 1 ha grid cells using fishnet tool in ArcGIS 10.2. We plotted the geo-coordinates collected during the group follow on these grid cells. The grid use was calculated as the proportion of the number of points in each grid cell to the total number of points recorded during each period. The proportion of the intensity of sleeping site use was calculated as the number of days each sleeping site was used among the total number of observation days in each period (Figure 2). The day range length (DRL) was calculated by joining the consecutive locations taken during the group follow using the geospatial modelling environment (GME) extension ${ }^{36}$ for ArcGIS 10.2. To estimate DRL, only the follows for a minimum of eight hours of the observation period in a day were used, and the length was measured using a field calculator in ArcGIS 10.2. The home range of the study group was estimated by adding the area of all the grid cells visited by the study group for each period ${ }^{36}$. As we did not have a control period for seasonal influence on ranging behaviour, we utilized the data on home range use collected during the same period the following year (14 October 2014 to 27 January 2015) as control and compared them with the post-rank changeover ranging data of 2013.

Reproductive behaviour: During the study period, the reproductive behavioural data were collected for $232.5 \mathrm{~h}$ (56 days), with $118.5 \mathrm{~h}$ (24 days) and $114 \mathrm{~h}$ (32 days) in the pre- and post-rank changeover periods respectively. Each day of the group follow was considered as one sample. The rates of different reproductive behaviours (mat- ing, female initiation, male initiation and mating by individual females) were computed using the number of each behaviour recorded against the number of observation hours of each day, and projected as number per hour of observation. The proportion of aggressive mating approaches by a male was computed as the number of aggressive approaches for mating by males divided by the total number of mating initiations by males each day. The rates of successful mating (copulation) of male and female or mating success in each day were estimated as the number of matings in a day divided by the total initiations on that day by males and females respectively.

Statistical analysis: The rates of reproductive behaviours, the DRL, and rates of encounters between the preand the post-rank changeover periods were compared using $t$-test. To calculate the grid use intensity, the percentages of recorded location points (geo-coordinates) of each grid were classified into five levels (not used, $\leq 0.6,0.7-6.6,6.7-10,>10$ ). The sleeping site use intensity was also categorized into five classes (not used, $\leq 2$, $2.1-5,5.1-10,>10)$ after calculating the percentage of sleeping records in each site. The percentages were calculated as the observed numbers in proportion to the total observations in the pre- and post-rank changeover within a gridded map to represent the home range and sleeping site use (Figure 2). To compare the pre- and the post-rank changeover intensity of grid cells and sleeping sites use, Wilcoxon signed-ranks test was used for the computed percentage of grids and sleeping sites independently. The use and not-use data of the total grids and sleeping sites (both pre- and post-rank changeover) were utilized in 
RESEARCH ARTICLES

Table 2. Demography and dynamics of study group (TR)

\begin{tabular}{|c|c|c|c|c|}
\hline \multirow[b]{3}{*}{$\begin{array}{l}\text { Age-sex class } \\
\text { (no. of individuals) }\end{array}$} & \multicolumn{4}{|c|}{ Events } \\
\hline & Pre-rank changeover & Rank changeover & Post-rank changeover & After post-rank changeover* \\
\hline & $\begin{array}{c}1 \text { July } 2013- \\
13 \text { October } 2013\end{array}$ & 14 October 2013 & $\begin{array}{l}15 \text { October } 2013- \\
31 \text { January } 2014\end{array}$ & $\begin{array}{l}1 \text { February } 2014- \\
31 \text { December } 2015\end{array}$ \\
\hline Adult males (4) & $\mathrm{HK}, \mathrm{RY}$ & FY(Ent), HK, RY & $\begin{array}{l}\text { FY, GP } \\
\text { (Ent - November 2013), } \\
\text { HK, RY }\end{array}$ & $\begin{array}{l}\text { FY, HK (Dis - May 2015), } \\
\text { P (Dis - May 2014), } \\
\text { RY (Ded-March 2014) }\end{array}$ \\
\hline Adult females (8) & $\begin{array}{l}\text { AU, BY, LA, NI, } \\
\text { PM, RE, SC, TE }\end{array}$ & $\begin{array}{l}\text { AU, BY, LA, NI, } \\
\text { PM, RE, SC, TE }\end{array}$ & $\begin{array}{l}\text { AU, BY, LA, NI, PM, } \\
\text { RE, SC, TE }\end{array}$ & $\begin{array}{l}\text { AU, BY, KU (Ent - April 2014, } \\
\text { Dis - June 2014), LA, NI, PM } \\
\quad \text { (Dis - December 2014), RE, SC, TE }\end{array}$ \\
\hline Sub-adult males (1) & MF & MF & MF & $\begin{array}{l}\text { BA (Dis - June 2015), } \\
\text { MF (Dis - August 2014), } \\
\text { KU, OE (Dis - July 2014), } \\
\text { UK (Dis - July 2014) }\end{array}$ \\
\hline Juvenile males (4) & $\mathrm{BA}, \mathrm{KU}, \mathrm{OE}, \mathrm{UK}$ & $\mathrm{BA}, \mathrm{KU}, \mathrm{OE}, \mathrm{UK}$ & BA, KU. OE, UK & AI \\
\hline Infant males (3) & $\mathrm{AI}, \mathrm{BN}, \mathrm{PT}$ & $\mathrm{AI}, \mathrm{BN}, \mathrm{PT}$ & $\begin{array}{l}\text { AI, BN, PT } \\
\quad(\text { Dis - November 2013) }\end{array}$ & $\begin{array}{l}\text { AY (Brn - June 2014), BA } \\
\text { (Brn - July 2014), BO } \\
\text { (Brn - May 2015), PY } \\
\text { (Brn - November 2014, } \\
\text { Dis - December 2014), } \\
\text { RI (Brn - February 2015), } \\
\text { TA (Brn - April 2015) }\end{array}$ \\
\hline Total & 18 & 19 & 20 & 24 (maximum in one time) \\
\hline
\end{tabular}

*After post-rank changeover period: age-class is provided as last seen in the group. Brn, Born; Ded, Died; Dis, Disappear from the group; Ent, Enter into the group.

McNemar binomial test to compare grid use and sleeping site use ${ }^{44,45}$. We used IBM SPSS v22 and R v3.2.2 statistical language with IDE R Studio v0.947 for statistical analysis.

\section{Results}

\section{Rank changeover event}

An alpha male replacement was observed on 14 October 2013, with an outside male named FY successfully challenging the resident alpha male RY, leading to an alpha male change (henceforth called rank changeover). During challenge, the former alpha male (RY) got severely injured, did not recover and died on March 2014. After this rank changeover event till December 2015, two previously unknown individuals, viz. one adult male (now named GP) and one adult female (now named KB) immigrated, while ten individuals, including the immigrated individuals, viz. two adult males (GP and HK), four subadult males (UK, OE, MF, and BA), two adult females (KB and PM) and two male infants (PT and PY) disappeared from the group. PM also left the group with her one-month-old infant (PY) on 10 December 2014 (Table 2). All individuals that emigrated from the group were not traceable in the vicinity.

\section{Ranging pattern}

The home range size (number of grids used) of the study group was 34 ha for the seven months of rank changeover study period, where 18 grids were used in both pre- and post-rank changeover periods, and the pre- and the postrank changeover grid use was 32 and 21 ha respectively, which differed significantly (two-tailed McNemar binomial test: $P<0.01$; Figure 2) (Supplementary Table 1). However, the intensity of grid use did not differ significantly between the pre- and post-rank changeover (Wilcoxon signed-ranks test: $Z=0.523, P=0.601$ ). The number of grids used in post-rank changeover was significantly smaller than that used in the pre-rank changeover period, and also in the same period in the next year (which was considered as control for the seasonal influence on ranging pattern; two-tailed McNemar binomial test: $P<0.01$; Figure 2) (Supplementary Table 2). The study group used 16 sleeping sites during the study period (Figure 2), where four sleeping sites were used in both pre and post-rank changeover periods. The number of sleeping sites during the pre- and post-rank changeover periods $(N=11$ and $N=9$ respectively) did not differ in a statistically significant way (two-tailed McNemar binomial test: $P=0.780$; Supplementary Table 1). The intensity of use of the sleeping sites also did not differ 
Table 3. Females' first sexual swelling, conception and birth according to the rank changeover event in a study group of Nicobar long-tailed macaque

\begin{tabular}{|c|c|c|c|c|}
\hline $\begin{array}{l}\text { Female } \\
\text { id }\end{array}$ & $\begin{array}{l}\text { Reproductive status on } \\
\text { acquisition period }\end{array}$ & $\begin{array}{l}\text { Presence of swelling on } \\
\text { acquisition period (yes/no) }\end{array}$ & $\begin{array}{c}\text { First appearance of sexual } \\
\text { swelling after acquisition (weeks) }\end{array}$ & $\begin{array}{l}\text { Conception date of post- } \\
\text { acquisition first birth from } \\
\text { acquisition period (weeks) }\end{array}$ \\
\hline $\mathrm{AU}$ & Lactating & No & 2 & 10 \\
\hline BY & Lactating & No & 3 & 15 \\
\hline LA & Non-receptive & No & 3 & - \\
\hline NI & Receptive & Yes & 3 & - \\
\hline RE & Receptive & Yes & 3 & 46 \\
\hline $\mathrm{SC}$ & Non-receptive & No & 7 & - \\
\hline TE & Non-receptive & No & 4 & 51 \\
\hline
\end{tabular}

between the pre- and post-rank changeover periods (Wilcoxon signed-ranks test: $Z=0.523, P=0.715$ ). Further, the sleeping sites after rank changeover were largely confined to the centre of the home range. DRL in the pre$\left(999.18 \mathrm{~m} \pm 225.52_{\mathrm{SD}}\right)$ and post-rank (981.87 $\mathrm{m} \pm$ $\left.200.16_{\mathrm{SD}}\right)$ changeover periods also did not differ $(t=0.195, \mathrm{~d} f=25, P=0.874)$.

\section{Between-group interactions}

The number of between-group interactions in the pre- and post-rank changeover periods was 11 and 9 respectively. The rate of between-group interactions did not differ between the pre- and post-rank changeover periods, which were 0.026 and $0.018 \mathrm{~h}^{-1}$ respectively $(N=20$, $t=0.887, \mathrm{~d} f=109, P=0.377)$. The aggressive betweengroup interactions $(N=10)$ in the post-rank changeover period $\left(N=3,0.005 \mathrm{~h}^{-1}\right)$ were lesser than in the pre-rank changeover period $\left(N=7,0.017 \mathrm{~h}^{-1}\right)$. However, both the non-aggressive and aggressive between-group interactions did not differ between the pre- and post-rank changeover periods (non-aggressive: $N=10$, pre $=4$, post $=6$, $t=0.40, \mathrm{~d} f=109, P=0.680$; aggressive: $N=10$, pre $=7$, post $=3, t=1.56, \mathrm{~d} f=109, P=0.120$ ).

\section{Reproductive behaviour}

During the rank changeover period, three of the eight females were lactating, two were cycling (reddening of the tail-root and anogenital skin), and three were noncycling. From the rank changeover day, a lactating female AU mated with FY after leaving her eight-monthold infant with the group, while the other two lactating females BY and PM were carrying infants of aged eight and nine months respectively. The other females avoided mating approaches by FY by participating in a group defence coalition with other females and males. Subsequently, aggression decreased, and all females except PM started soliciting FY within two weeks after the rank changeover. On 17 November 2013, a severe fight occurred between FY and PM in a bush and PM was severely injured. Thereafter, about a month old male infant PT of PM was not found. PM started mating with FY only after the disappearance of her infant. After the rank changeover, until December 2015, six of those eight females gave birth. We calculated the post-rank changeover first conception date of six females by backcalculating 165 days gestation period from parturition day $^{46}$, which ranged between 11 and 51 weeks with a mean of $30.6 \pm 16.3_{\mathrm{SD}}$ weeks from the day of rank changeover (Table 3). This shows that no female became pregnant in a first sexual swelling phase following the post-rank changeover.

The number of matings observed in the pre- and postrank changeover periods was 55 and 117 respectively, and the number of matings per hour was significantly higher during the post-rank changeover period than the pre-rank changeover period $(t=4.88, \mathrm{~d} f=54, P<0.001)$. In the pre-rank changeover period, RY (83.64\%) was involved in a higher number of matings than in the postrank changeover period. However, in the post-rank changeover period, FY showed maximum mating (77.78\%) while no mating was observed by RY. The rate of mating initiated by adult females between the pre- $\left(0.30 \mathrm{~h}^{-1}\right)$ and the post-rank $\left(0.33 \mathrm{~h}^{-1}\right)$ changeover periods did not differ $(t=0.36, \mathrm{~d} f=54, P=0.742)$ (Figure 3$)$. The rate of matings initiated by a male differed significantly between the pre- $\left(0.27 \mathrm{~h}^{-1}\right)$ and post-rank $\left(1.01 \mathrm{~h}^{-1}\right)$ changeover periods $(t=-5.05, \mathrm{~d} f=54, P<0.001)$ (Figure 3$)$. The proportion of aggressive mating approaches by a male was significantly higher during the post-rank changeover period than the pre-rank changeover period $(t=-4.26$, $\mathrm{d} f=54, P<0.001)$. The rate of mating success of females and males in the pre- and post-rank changeover periods did not differ (female: $t=1.27, \mathrm{~d} f=54, P=0.211$; male: $t=1.00, \mathrm{~d} f=54, P=0.32)$. Although the rate of mating with all the adult females increased during the post-rank changeover period, significant increase was seen with AU $(t=2.462, \mathrm{~d} f=54, P=0.017), \mathrm{BY}(t=3.484, \mathrm{~d} f=54$, $P=0.001)$, LA $(t=2.00, \mathrm{~d} f=54, P=0.05)$ and $\mathrm{NI}$ $(t=2.08, \mathrm{~d} f=54, P=0.007)$ (Figure 4). 


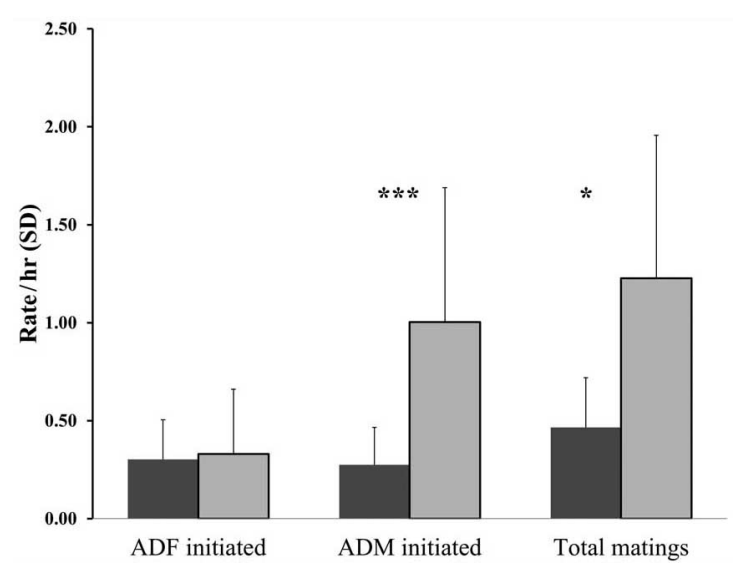

Figure 3. Frequency of mating initiation by adult female (ADF-initiated), mating initiation by adult male (ADM-initiated) and total number of matings observed during pre- and post-rank changeover in the study group TR (dark columns represent pre-rank changeover mating initiation rates and mating rates, while light columns represent post-rank changeover mating initiation rates and mating rates; $* P<0.05, * * P<0.005, * * * P<0.001)$.

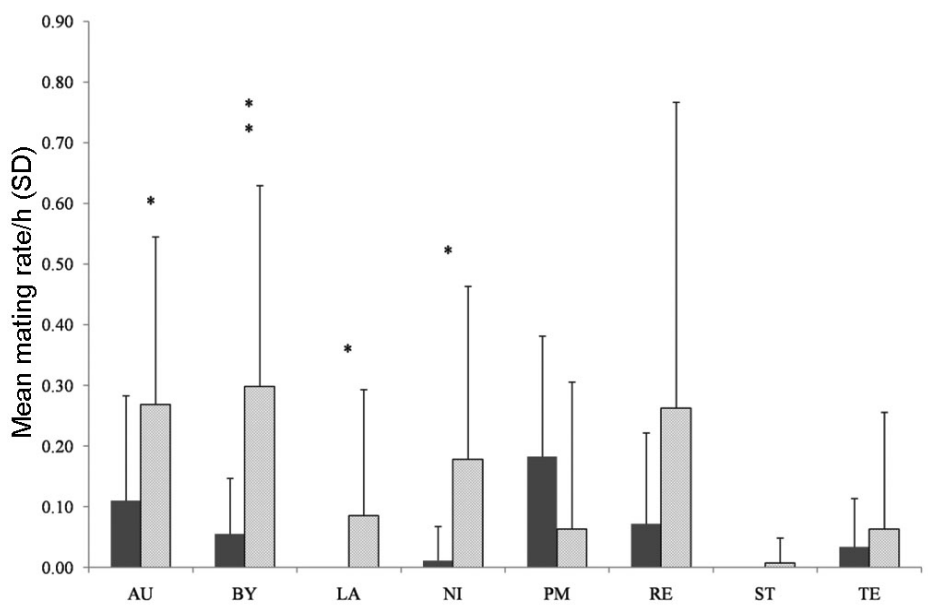

Figure 4. Matings rates with individual females during pre- and post-rank changeover in the study group TR (dark columns represent pre-rank changeover mating rates, while light columns represent post-rank changeover mating rates; ${ }^{*} P<0.05, * * P<0.005$ ).

\section{Discussion}

We recorded one rank changeover event by an outside male in a wild Nicobar long-tailed macaque group during a 30 months study at the Great Nicobar Island. The intensity of grid use and DRL of the study group did not change after the rank changeover event, though the group used significantly lesser grids after the event than in the pre-rank changeover. The rate of between-group interactions did not change after the rank changeover, although the rate of aggressive encounters was lower than in the pre-rank changeover event. The overall mating rate increased significantly with a higher rate of overall and aggressive mating approaches by the new male in the post-rank changeover period than by the previous alpha male during the pre-rank changeover period. However, the rate of mating success was not different in the two periods. The mating rates of all adult females increased significantly after the rank changeover, except for one female
(PM). These findings add to the growing knowledge on rank changeovers and the resulting changes in behaviour.

A shift and decrease in grid use and sleeping sites were observed after the rank changeover. The ranging data of the post-rank changeover differed from the next year's control data, which nullifies seasonality as a causal factor of change in the post-rank changeover ranging pattern. Although the group used significantly smaller area in the post-rank changeover period than in the pre-rank changeover period, DRL did not vary, which indicates that the group moved, constantly changing positions in a smaller area than before the rank changeover. This could have resulted in a change in the ranging pattern as a strategy to avoid interaction with neighbouring groups, as seen in Papio cynocephalus ${ }^{47}$ and Nilgiri langurs ${ }^{34}$.

The group cohesion and coordination became weaker due to post-rank changeover due to aggressive and restrictive social interactions between the immigrant male and other individuals ${ }^{12}$. The new male was recorded to 
stay in the periphery of the group in the case of Macaca fuscata $^{48}$ and Alouatta pigra ${ }^{49}$, which may be a strategy to avoid coalitionary aggression of the group or of the resident males. The defeated male became peripheral and stayed away from the new male by forming a subgroup with natal males, and sometimes with lactating and pregnant females (e.g. M. fascicularis fascicularis ${ }^{7}$ and $M$. fuscata $^{50}$ ). Therefore, during the post-rank changeover, weak social coordination may increase the risk of intergroup encounters. During the present study, opting to use a smaller home range size and shift in the location of sleeping sites in post-rank changeover by the group may be a strategy adopted to avoid interaction with other groups in this disturbed social state. The decreased aggressive interactions in the post-rank changeover period supported encounter avoidance, though this inference should be viewed with a little caution due to small sample size in the present study.

The changes of group membership by adult males after rank changeover directly affected the toppled male. Frequent competition between the new prime male and the deposed male took place, and such competition eventually was biased towards the new prime male for his physical or fighting ability. After being defeated, the toppled male may stay in the group as a submissive individual or emigrate immediately ${ }^{27}$. Emigration of males due to the rank changeover is common in Cebus capucinus, and rank changeover is considered as the most important factor that induces dispersal of native males in the species $^{51}$. The ousted male remains as a submissive or a peripheral individual with the same group in some of the macaque species, e.g. M. fascicularis fascicularis ${ }^{11}$, M. silenus ${ }^{9}$ and $M$. radiata ${ }^{10}$ ). The ousted male RY in the present study remained in the group as a submissive male to FY. Due to severe injuries and disabilities after the fight, the movement of RY was restricted to the ground; thus being a submissive male in the current group may have been a more beneficial strategy on its part than to emigrate.

An increased mating rate and aggressive mating approaches by a new male can be attributed to the imposition of an acquired dominance over the group. Previous studies reported that male-initiated copulations increased significantly after a rank, changeover ${ }^{50,52}$. Meanwhile, females show situation-dependent receptiveness, and they mated at a high rate with the immigrated male ${ }^{18,19,30}$. The increased mating rate has been considered as a female counter-strategy to minimize aggression and aggressive mating approaches from the new male in the post-rank changeover period ${ }^{15,53}$. A similar pattern of high mating frequency was observed in all adult females, except PM in the study group. Female long-tailed macaques show conspicuous sexual swelling between January and May followed by copulation peak between January and June ${ }^{46}$. It may be noted that the rank changeover event in the present study occurred in October, which is in the middle of the birth season when mating frequency is expected to be the lowest. At that time, three females were in lactating phase. The high mating frequency, therefore, was a consequence of mating initiation by the new male. If the unweaned offspring get accidentally or strategically killed, the new male may increase mating initiation as a strategy to mate with the female whose infant got killed and jeopardize the reproductive output of the current male.

After an agonistic interaction with the new alpha male FY, the female PM was severely injured and her infant PT went missing. Although the reason for the infant disappearance could not be ascertained, it most likely resulted from infanticide. As studies indicate, infanticide by a new male is another widespread behaviour occurring during rank changeover, which is found in both wild and captive long-tailed macaque populations ${ }^{5,54}$. Infanticide by a new male is a widespread strategy in primate societies to access lactating females by disrupting their lactational amenorrhea (e.g. Semnopithecus entellus ${ }^{16,55}$ and Theropithecus gelad ${ }^{56}$ ). Many studies have shown that after infanticide, mothers become receptive and have shorter inter-birth interval than average ${ }^{56}$. However, the female long-tailed macaques adopt strategies like prolonged receptiveness, post-conception copulation and promiscuous mating, which decrease the chance of infanticide by increasing paternity confusion ${ }^{32}$. Furthermore, in the case of non-seasonal breeders, where the immigrated male is unrelated to the infants and where the females get receptive after the infant loss, infanticide may increase the reproductive benefit to the immigrated male ${ }^{5}$.

At the time of rank changeover in the study group, only two of the eight females were cycling. Just after the rank changeover, only one lactating female AU was involved in soliciting FY after leaving her infant AI. This sudden decrease in maternal care after the resumption of sexual activity of a mother is common in many macaque societies (e.g. M. mulatta ${ }^{57}$ and M. fuscata $^{58}$ ). Except AU, all other females adopted a group defence strategy by forming a coalition with the other females and males to avoid aggressive mating approach from the immigrated male. In some of the primate species, females were observed to form a defensive alliance with the toppled male or with other group males which may have helped them avoid aggressive mating approaches by the new male ${ }^{59}$. Within two weeks after the rank changeover, except PM, all females were soliciting FY, developed anogenital swelling of different intensity and started mating with the new alpha male, which consequently increased the post-rank changeover mating rate. The failure of PM to ensure the survival of her infant by resisting FY, may indicate that resisting was neither a low-cost nor an effective strategy. The sexual swelling is a graded indicator of female receptivity ${ }^{60}$; however, no female conceived in the first postrank changeover cycle, which may indicate that the swelling was deceptive. The two lactating females, viz. AU and BY adopted this deceptive swelling strategy and were 
able to secure the survival of their infants without breaking the post-partum amenorrhea or getting pregnant. Therefore, it could be suggested that like M. fascicularis fascicularis $^{61}$, the female Nicobar long-tailed macaques also successfully use situation-dependent swelling as a counterstrategy against agonistic approach by the immigrated male. After exhibiting pseudo-cycling, the females also mated with two other males in the group. These swellings are deceptive and not associated with ovarian cycles, since the mating did not result in fertilization. Primate females widely use this promiscuous polyandrous mating as a reproductive strategy to protect themselves and their offspring through paternity confusion (M. fascicularis $^{5}$ and Alouatta seniculus ${ }^{62}$ ). Thus, the females in the study group were observed to adopt different strategies with respect to their reproductive status to minimize the cost incurred due to the rank changeover. Emigration and immigration of several individuals following the rank changeover event in the present study indicated social instability, which has also been reported in other macaques (e.g. M. radiata ${ }^{10}$ ).

The present study reveals how a single event of rank changeover by challenge has repercussions which cascade from the individual level to the cumulative group level changes in behaviour. In other words, the sexual strategy of a new alpha male is countered by different strategies employed by the individuals of different age-sex and reproductive stages, which ultimately manifest as altered reproductive behaviours and home range use patterns. In this way, co-evolving sexual strategies and counter strategies contribute towards emergent complexities in primate societies.

1. Clutton-Brock, T. H. and Huachard, E., Social competition and selection in males and females. Philos. Trans. R. Soc. London, Ser. B, 2013, 368, 20130074.

2. Albert, S. C., Magnitude and source of variation in male reproductive performance. In The Evolution of Primate Societies (eds Mitani, J. C. et al.), University of Chicago Press, Chicago, USA, 2012, pp. 412-431.

3. Kappeler, P. M. and van Schaik, C. P., Evolution of primate social systems. Int. J. Primatol., 2002, 23, 707-740.

4. van Noordwijk, M. A. and van Schaik, C. P., Sexual selection and the careers of primate males: paternity concentration, dominanceacquisition tactics and transfer decision. In Sexual Selection in Primates: New and Comparative Perspectives (eds Kappeler, P. M. and van Schaik, C. P.), Cambridge University Press, Cambridge, UK, 2004, pp. 208-229.

5. deRuiter, J. R., van Hooff, J. A. R. A. M. and Scheffrahn, W., Social and genetic aspects of paternity in wild long-tailed macaques (Macaca fascicularis). Behavior, 1994, 129, 203-224.

6. van Schaik, C. P. and Janson, C. H., Infanticide by Males and its Implications, Cambridge University Press, Cambridge, UK, 2000, p. 565.

7. van Noordwijk, M. A. and van Schaik, C. P., Male migration and rank acquisition in wild long-tailed macaque. Anim. Behav., 1985, 33, 849-886.

8. Marty, P. R., Hodges, K., Agil, M. and Engelhardt, A., Alpha male replacements and delayed dispersal in crested macaques (Macaca nigra). Am. J. Primatol., 2017, 79, e22448.
9. Kumar, M. A., Singh, M., Kumara, H. N., Sharma, A. K. and Bertsch, C., Male migration in lion-tailed macaques. Primate Rep., 2001, 59, 5-18.

10. Singh, M., Kumara, H. N., Kumar, M. A., Singh, M. and Cooper, M., Male influx, infanticide, and female transfer in Macaca radiata radiata. Int. J. Primatol., 2006, 27, 515-528.

11. van Noordwijk, M. A. and van Schaik, C. P., Male careers in Sumatran long-tailed macaques (Macaca fascicularis). Behaviour, 1988, 10, 24-43.

12. Hayakawa, S. and Soltis, J., Troop takeover and reproductive success of wild male Japanese macaques on Yakushima island (Macaca fuscata yakui). Int. J. Zool., 2011, 308469, 1-8.

13. Saj, T. L. and Sicotte, P., Male takeover in Colobus vellerosus at Boabeng-Fiema Monkey Sanctuary, Central Ghana. Primates, 2005, 46, 211-214.

14. Clarke, P. M. R., Henzi, S. P. and Barrett, L., Sexual conflict in chacma baboons, Papio hamadryas ursinus: absent males select for proactive females. Anim. Behav., 2009, 77, 1217-1225.

15. Smuts, B. B. and Smuts, R. W., Male aggression and sexual coercion of females in nonhuman primates and other mammals: evidence and theoretical implications. Adv. Stud. Behav., 1993, 22, $1-63$.

16. Hrdy, S. B., Male-male competition and infanticide among the langurs (Presbytis entellus) of Abu, Rajasthan. Folia Primatol., 1974, 22, 19-58.

17. Hrdy, S. B., Infanticide as a primate reproductive strategy. Am. Sci., 1977, 65, 40-49.

18. Hrdy, S. B., Infanticide among animals: a review, classification, and examination of the implications for the reproductive strategies of females. Ethol. Sociobiol., 1979, 1, 13-40.

19. Zinner, D. and Deschner, T., Sexual swellings in female hamadryas baboons after male takeovers: 'deceptive' swellings as a possible female counter-strategy against infanticide. Am. J. Primatol., 2000, 52, 157-168.

20. Hadidian, J. and Bernstein, I. S., Female reproductive cycles and birth data from an Old World monkey colony. Primates, 1979, 20, $429-442$.

21. Colmenares, F. and Gomendio, M., Changes in female reproductive condition following male take-overs in a colony of hamadryas and hybrid baboons. Folia Primatol., 1988, 50, 157-174.

22. Takahata, Y., Ihobe, H. and Idani, G., Comparing copulations of chimpanzees and bonobos: do females exhibit proceptivity or receptivity? In Great Apes Societies (eds McGrew, W. C., Marchant, L. F. and Nishida, T.), Cambridge University Press, Cambridge, UK, 1996, pp. 146-155.

23. Swedell, L., Two takeovers in wild hamadryas baboons. Folia Primatol., 2000, 71, 169-172.

24. Teichroeb, J. A. and Sicotte, P., Infanticide in ursine colobus monkeys (Colobus vellerosus): new cases and a test of the existing hypotheses. Behaviour, 2008, 145, 727-755.

25. Zhao, Q., Borries, C. and Pan, W., Male takeover, infanticide, and female counter tactics in white-headed leaf monkeys (Trachypithecus leucocephalus). Behav. Ecol. Sociobiol., 2011, 65, 15351547.

26. Sterck, E. H. M. and Korstjens, A. H., Female dispersal and infanticide avoidance in primates. In Infanticide by Males and its Implications (eds van Schaik, C. P. and Janson, C. H.), Cambridge University Press, Cambridge, UK, 2000, pp. 293-321.

27. van Noordwijk, M. A. and van Schaik, C. P., Career moves: transfer and rank challenge decisions by male long-tailed macaques. Behaviour, 2001, 138, 359-395.

28. Sprague, D. S., Suzuki, S., Takahashi, H. and Sato, S., Male life history in natural populations of Japanese macaques: migration, dominance rank, and troop participation of males in two habitats. Primates, 1998, 39, 351-363.

29. Velankar, A. D., Kumara, H. N., Pal, A., Mishra, P. S. and Singh, M., Population recovery of Nicobar long-tailed macaque Macaca 
fascicularis umbrosus following a tsunami in the Nicobar Islands, India. PLOS ONE, 2016, 11(2), e0148205; doi:10.1371/journal. pone.0148205.

30. van Noordwijk, M. A. and van Schaik, C. P., The effect of dominance rank and group size on female life-time reproductive success in wild long-tailed macaque Macaca fascicularis. Primates, 1999, 40, 105-130.

31. Thierry, B., Social epigenesis. In Macaque Societies: A Model for the Study of Social Organization (eds Thierry, B., Singh, M. and Kaumanns, W.), Cambridge University Press, Cambridge, UK, 2004, pp. 267-294.

32. van Schaik, C. P., Social counterstrategies against male infanticide in primates and other mammals. In Primate Males (ed. Kappeler, P. M.), Cambridge University Press, Cambridge, UK, 2000, pp. 34-52.

33. Palombit, R. A., Infanticide as sexual conflict: coevolution of male strategies and female counterstrategies. CSH Perspect. Biol., 2015; doi:10.1101/cshperspect.a017640.

34. Kavana, T. S., Erinjery, J. J. and Singh, M., Male takeover and infanticide in Nilgiri langur Semnopithecus johnii in the Western Ghats, India. Folia Primatol., 2014, 85, 164-177.

35. Hajra, P. K., Rao, P. S. N. and Sinha, B. K., Flora of Great Nicobar Islands, Botanical Survey of India, Calcutta, 1999.

36. Santhosh, K., Kumara, H. N., Velankar, A. D. and Sinha, A., Ranging behaviour and resource use by lion-tailed macaques (Macaca silenus) in selectively logged forests. Int. J. Primatol., 2015, 36, 288-310

37. Tsuji, Y., Sleeping-site preferences of wild Japanese macaques (Macaca fuscata): the importance of nonpredatory factors. J. Mammal., 2011, 92, 1261-1269.

38. Altmann, J., Observational study of behaviour: sampling methods. Behaviour, 1974, 49, 227-265.

39. Cooper, M. A., Aureli, F. and Singh, M., Between-group encounters among bonnet macaques (Macaca radiata). Behav. Ecol. Sociobiol., 2004, 56, 217-227.

40. Kumara, H. N., Singh, M., Sharma, A. K., Santhosh, K. and Pal, A., Impact of forest fragment size on between-group encounters in lion-tailed macaques. Primates, 2015, 55, 543-548.

41. Kowalewski, M. M. and Garber, P. A., Mating promiscuity and reproductive tactics in female black and gold howler monkeys (Alouatta caraya) inhabiting an island on the Parana river, Argentina. Am. J. Primatol., 2010, 71, 1-15.

42. Jones, C. B., Reproductive patterns in mantled howler monkeys: estrus, mate choice and copulation. Primates, 1985, 26, 130-142.

43. Soltis, J., Mitsunaga, F., Shimizu, K., Yanagihara, Y. and Nozaki, M., Sexual selection in Japanese macaques. I: female mate choice or male sexual coercion? Anim. Behav., 1997, 54, 725-736.

44. Price, E. C. and Piedade, H. M., Ranging behaviour and intraspecific relationships of masked titi monkeys (Callicebus personatus personatus). Am. J. Primatol., 2001, 53, 87-92.

45. Fei, H. L., Scott, M. B., Zhang, W., Ma, C. M., Xiang, Z. F. and Fan, P. F., Sleeping tree selection of caovit gibbon (Nomascus nasutus) living in degraded karst forest in Bangliang, Jingxi, China. Am. J. Primatol., 2012, 74, 998-1005.

46. van Noordwijk, M. A., Sexual behaviour of Sumatran long-tailed macaques (Macaca fascicularis). Z. Tierpsychol., 1985, 70, 277-296.

47. Markham, A. C., Alberts, S. C. and Altmann, J., Intergroup conflict: ecological predictors of winning and consequences of defeat in a wild primate population. Anim. Behav., 2012, 84, 399403.

48. Horiuchi, S., Affiliative relations among male Japanese macaques (Macaca fuscata yakui) within and outside a troop on Yakushima Island. Primates, 2005, 46, 191-197.

49. van Belle, S., Kulp, A. E., Thiessen-Bock, R., Garcia, M. and Estrada, A., Observed infanticides following a male immigration event in black howler monkeys, at Palenque National Park, Mexico. Primates, 2010, 51, 279-284.

50. Hayakawa, S., Female defensibility in a small troops of Japanese macaques vis-à-vis nontroop males and copulation on the periphery of the troop. Int. J. Primatol., 2007, 28, 73-96.

51. Jack, K. M., Sheller, C. and Fedigan, L. M., Social factors influencing natal dispersal in male white-faced capuchins. Am. J. Primatol., 2012, 74, 359-365.

52. Roux, A., Snyder-Mackler, N., Roberts, E. A., Beehner, J. C. and Bergman, T. J., Evidence for tactical concealment in a wild primate. Nature Commun., 2013, 4, 1462.

53. Muller, M. N. and Wrangham, R. W., Sexual Coercion in Primates and Humans: An Evolutionary Perspective on Male Aggression Against Females, Harvard University Press, Cambridge, Massachusetts, USA, 2009, p. 475.

54. Timmerman, P. J. A., Schouter, W. G. P. and Krijnen, J. C. M., Reproduction of cynomolgus monkeys (Macaca fascicularis) in harems. Lab Anim., 1981, 13, 119-123.

55. Sugiyama, Y., On the social change of Hanuman langurs (Presbytis entellus) in their natural condition. Primates, 1965, 6, $381-418$.

56. Beehner, J. C. and Bergman, T. J., Infant mortality following male takeovers in wild geladas. Am. J. Primatol., 2008, 70, 1152-1159.

57. Berman, C. M., Rasmussen, K. L. R. and Suomi, S. J., Reproductive consequences of maternal care patterns during estrus among free ranging rhesus monkeys. Behav. Ecol. Sociobiol., 1993, 332, 391-399.

58. Schino, G., Majolo, B., Ventura, R. and Troisi, A., Resumption of sexual activity affects mother-infant interactions in Japanese macaques. Behaviour, 2001, 138, 261-275.

59. Rudran, R., Adult male replacement in one-male troops of purplefaced langurs (Presbytis senexsenex) and its effect on population structure. Folia Primatol., 1973, 19, 166-192.

60. Nunn, C. L., The evolution of exaggerated sexual swellings in primates and the graded signal hypothesis. Anim. Behav., 1999, 58, 229-246.

61. Engelhardt, A., Hodges, J. K., Niemitz, C. and Heistermann, M., Female sexual behaviour, but not sex skin swelling is a reliable indicator for the timing of the fertile phase in wild long-tailed macaques (Macaca fascicularis). Horm. Behav. 2005, 47, 195204.

62. Agoramoorthy, G. and Rudran, R., Infanticide by adult and subadult males in free ranging red howler monkeys, Alouatta seniculus, in Venezuela. Ethology, 1995, 99, 75-88.

ACKNOWLEDGEMENTS. This study was supported by the Department of Science and Technology (DST), Government of India (GoI) (Grant No. SR/SO/AS-49/2011) to H.N.K. and the INSPIRE Fellowship, DST (Grant No. A.20020/11/97-IFD.DT.31.03.2010) to A.P., M.S. and P.S.M. thank the Science and Engineering Research Board, GoI for award of J. C. Bose Fellowship (Grant No. SB/S2/JCB056/2015) during which this article was prepared. We thank the Department of Environment and Forests, Andaman \& Nicobar Administration for granting permits to carry out the field work (Permit No. CWLW/WL/134/566); Dr P. A. Azeez (former Director), and Dr K. Sankar (Director), Sálim Ali Centre for Ornithology and Natural History, Coimbatore for encouragement and support, and the two anonymous reviewers for their valuable comments that helped improve the manuscript.

Received 20 June 2018; revised accepted 4 May 2019

doi: $10.18520 / \mathrm{cs} / \mathrm{v} 117 / \mathrm{i} 4 / 672-682$ 